\title{
Рівняння стану конденсованого метану при високих тисках
}

\author{
Л. М. Якуб, О. С. Бодюл
}

Одеська національна академія харчових технологій, вул. Канатна, 112, м. Одеса, 65039, Україна

\begin{abstract}
В роботі запропоновано теоретичне рівняння стану рідкого метану, побудоване в рамках теорії збурення, де в якості нульового наближення виступає флюїд Леннард-Джонса, а в якості потенціалу збурення - октупольоктупольна взаємодія молекул метану. Рівняння стану рідкого метану дозволяє описати його термодинамічні властивості на лінії плавлення і передбачити їх з достатньою точністю в області високого тиску, де практично відсутні експериментальні дані. Термодинамічні властивості рідкого метану розраховані в иирокому діапазоні температур (100-300 К) і тисків (1-1000 МПа). Для розрахунку було задано лише три параметри: два параметра потенціалу Леннард-Джонса і октупольний момент молекули метану. Рівняння стану метану внесено в автоматизовану систему розрахунку теплофізичних властивостей речовин «ThеrтоРro-5». Наведено результати розрахунку густини, ентальпї, ентропї, коефічієнта теплового розширення, стисливості і теплоємності. Можливості запропонованого теоретичного рівняння стану, щзо не залучає експериментальних даних, а також оцінки точності отриманих даних, дозволяють значно розширити область дослідження рідкого метану до високих тисків понад 1000 МПа.
\end{abstract}

Ключеві слова: метан, рівняння стану, високі тиски, лінія плавлення.

(C) The Author(s) 2018. This article is an open access publication

This work is licensed under the Creative Commons Attribution 4.0 International License (CC BY) http://creativecommons.org/licenses/by/4.0/

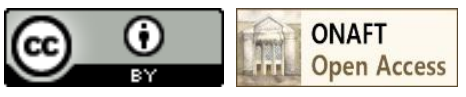

\section{1 Вступ}

При транспортуванні, зберіганні, зріджуванні або розділенні природного газу необхідна інформація про термодинамічні властивості метану. Він $є$ основним компонентом в сумішах природних вуглеводнів. При використанні технологічних процесів переробки метану необхідні дані про його термодинамічні властивості при високих температурах і тисках. При експлуатації апаратури, що використовується для очищення метану, також потрібні точні дані про його властивості при низьких температурах як в газовій, так і в рідкій фазах.

Метою даної роботи $є$ розробка теоретичного рівняння стану рідкого метану, що дозволить розраховувати його термодинамічні властивості в області високих тисків і низьких температур без використання експериментальних даних.

Теоретичному і експериментальному дослідженням термодинамічних властивостей метану присвячена велика кількість робіт, що виключає їх докладний розгляд в рамках даної статті. Слід зазначити тільки відомі фундаментальні монографії присвячені властивостям метану $[1,2]$. Нижче буде проведено порівняння результатів розрахунку густини за запропонованим рівнянням стану $з$ даними, наведеними в цих роботах.

В роботі [1] використовується відоме єдине рівняння стану метану, представлене у вигляді подвійного розкладання стисливості за ступенями густини і температури. В роботі [2] автори представляють рівняння стану метану у вигляді фундаментального рівняння, що визначає вільну енергію Гельмгольца. Функція, що апроксимує вільну енергію Гельмгольца, містить 40 під- гінних коефіцієнтів і була представлена в [2] із залученням окремих експериментальних даних за рядом теплофізичних властивостей. Рівняння стану відповідає новій міжнародній температурній шкалі 1990 року (ITS-90) і екстраполюється до тиску 20000 МПа.

Підхід, використаний при побудові рівнянь стану в роботах $[1,2]$, заснований на використанні великого масиву експериментальних даних. Це дозволяє розширити інтервал застосування рівнянь при розрахунку термодинамічних властивостей і підвищити точність. У той же час, ці рівняння мають велике число констант, i форма їх подання викликає утруднення при спробі їх використання в разі відновлення ліній плавлення і затвердіння. При проведенні розрахунків термодинамічних властивостей використовувалися емпіричні рівняння стану, такі як, наприклад, рівняння стану Бенедикта - Вебба-Рубіна 333 підгінними параметрами [3]. Основна концепція еталонних емпіричних рівнянь стану полягає в тому, що одне рівняння має описувати всі експериментальні дані щодо термодинамічних властивостей, відомих для певної фази (рідини або твердого тіла) в межах їх експериментальної невизначеності.

Існують також інші підходи до побудови рівнянь стану, що не мають згаданих недоліків, наприклад, засновані на термодинамічній теорії збурень (ТТ3) $[4,5]$. Перша послідовна теорія рідин на основі ТТЗ була запропонована Баркером і Хендерсоном понад п'ятдесят років тому [4]. Кілька років по тому Андерсен, Чандлер і Вікс [5] розробили дещо іншу теорію рідини на основі термодинамічної теорії збурення.

Нижче зроблена спроба побудови на цій основі рівняння стану рідкого метану, що дозволяє описати його 
термодинамічні властивості на лінії плавлення і передбачити їх 3 достатньою точністю в області високого тиску, де практично відсутні експериментальні дані.

В рамках ТT3 [6] в якості нульового наближення виступає флюїд, що складається зі сферичних молекул, які взаємодіють за допомогою потенціалу ЛеннардДжонса (12-6), а в якості збурення - октупольоктупольна взаємодія.

\section{2 Рівняння стану рідкого метану}

Для побудови рівняння стану рідкого метану в роботі була використана згадана вище ТТЗ $[4,6]$. Як вже було зазначено, в якості опорної системи був обраний флюїд Леннард-Джонса, а в якості збурення - октуполь-октупольна взаємодія молекул метану.

В рамках ТT3 вільна енергія подається як функція температури $T$ і об'єму $V$ у вигляді наступного ряду:

$$
F(V, T)=F^{(c \phi)}(V, T)+\left\langle\Delta U_{\text {несф }}\right\rangle-\frac{1}{2 R T}\left[\left\langle\Delta U_{\text {несф }}^{2}\right\rangle-\left\langle\Delta U_{\text {несф }}\right\rangle^{2}\right]+\ldots
$$

де $\left\langle\Delta U_{\text {несф }}\right\rangle$ - октуполь-октупольна взаємодія молекул метану, усереднена за орієнтаціями і функцією розподілу системи Леннард-Джонса 3 центральною взаємодією.

Основний внесок у вільну енергію Гельмгольца та інші термодинамічні функції становить перший доданок рівняння (1) $F^{(c \phi)}(V, T)$, що відповідає опорній системі. Потенціал Леннард-Джонса, який застосовується в даній роботі, безсумнівно, є самою популярною і видатною моделлю серед усіх реалістичних потенційних моделей, що використовуються в теоріях рідин.

Усереднення за орієнтацією проводиться так само, як і для системи вільних ротаторів. В цьому випадку мультипольна симетрія нецентральної взаємодії призводить до того, що поправка першого наближення $\left\langle\Delta U_{\text {несф }}\right\rangle$ наближається до нуля і оцінку впливу несферичності потенціалу взаємодії на термодинамічні властивості системи дає середнє значення квадрату октуполь-октупольної взаємодії $\left\langle\Delta U_{\text {несф }}^{2}\right\rangle$.

В роботі [7] термодинамічні властивості флюїду Леннард-Джонса були описані аналітично 3 використанням ТТЗ з точністю кращою, або, принаймні, порівняною с тою, яку дають емпіричні рівняння. Найкращий опис даних комп'ютерного моделювання флюїду Леннард-Джонса дає наступне рівняння стану для вільної енергії Гельмгольца, запропоноване в роботі [7]:

$$
F^{(c \phi)}\left(\rho^{*}, T^{*}\right)=f_{H S}(\eta)+e^{-\gamma \rho^{* 2}} \rho^{*} T^{*} \Delta B_{2 H S}+\sum_{i, j} C_{i j} T^{* i / 2} \rho^{* j}
$$

Рівняння для вільної енергії опорної системи $F^{(c \phi)}$ як функції зведеної густини $\rho^{*}$ і зведеної температури $T^{*}=k T / \varepsilon$ включає основний внесок $f_{H S}(\eta)$, який представляє собою зведену вільну енергію Гельмгольца рідкої системи твердих сфер 3 параметром упаковки $\left(\eta=1 / 6 \pi \rho^{*}\right)$. Другий член в правій частині рівняння (2) $\Delta B_{2 H S}$ представляє внесок так званого «залишкового другого віріального коефіцієнта», що враховує різницю між другими віріальними коефіцієнтами системи Леннард-Джонса і системи жорстких сфер. Остання сума враховує всі інші вклади у вільну енергію Гельмгольца. Коефіцієнти $C_{\mathrm{ij}}$ наведено в роботі [7].

Рівняння (2) досить точно відтворює термодинамічні властивості модельної рідини Леннард-Джонса в широкому діапазоні густини при зведених температурах до $T^{*}=3$. Воно визначає опорну систему та доповнено поправкою на октуполь-октупольну взаємодію. Для рідини октуполь-октупольний внесок можна записати у вигляді [8]:

$$
\left\langle\Delta U_{\text {oct }}^{2}\right\rangle=9.7846 \varepsilon^{2} \rho^{*}\left\langle r^{*-14}\right\rangle \Omega^{*} \varepsilon
$$

Тут $\Omega^{*}=\Omega / \sqrt{\varepsilon \sigma^{7}}-$ зведений октупольний момент молекули, $\mathrm{a}\left\langle r^{*-14}\right\rangle$ - усереднене значення 14-го ступеня наведеної зворотної відстані між центрами молекул, обчислене за відомою радіальною функцією розподілу системи Леннард-Джонса:

$$
\left\langle r^{*-14}\right\rangle=2 \pi \int \frac{g(r)}{r^{14}} r^{2} d r
$$

та апроксимоване у вигляді:

$$
\begin{aligned}
\left\langle r^{*-14}\right\rangle= & 0.2629-0.4357 \rho^{*}+0.4043 \rho^{* 2} \\
& +\left(0.01879+0.01127 \rho^{*}+0.07864 \rho^{* 2}\right) T^{*}
\end{aligned}
$$

Використовуючи цей вираз, можна підрахувати необхідні поправки до всіх термодинамічних функцій. В цю складову слід включити також відповідний кінетичний внесок за рахунок вільного обертання молекул метану.

Рівняння стану було успішно застосовано для розрахунку лінії плавлення метану в роботі [8], де також наведені результати розрахунку густини співіснуючих фаз, які порівнюються $з$ дослідними даними, представленими у роботі [9]. Результати передбачення лінії плавлення метану дозволяють використовувати рівняння стану для передбачення термодинамічних властивостей в області високих тисків.

\section{3 Термодинамічні властивості рідкого метану при високих тисках}

Термодинамічні властивості метану на лініях рівноваги фаз рідина-пар вивчені детально, проте дослідження властивостей на лінії затвердіння нечисленні, що пов'язано 3 методичними труднощами, а в області 
високих тисків - 3 експериментальними можливостями вимірювань.

Для розрахунку термодинамічних властивостей рідкого метану потрібно задати тільки три параметри: два параметра потенціалу Леннард-Джонса $\varepsilon$ та $\sigma$ i октупольний момент молекули метану $\Omega$.

У літературі відомий цілий ряд параметрів потенціалу Леннард-Джонса (12-6), що апроксимують взаємодію $\mathrm{CH}_{4}-\mathrm{CH}_{4}$. Однак ці значення, як правило, враховують і ефективну октуполь-октупольну взаємодію. 3 огляду на те, що внесок останнього зменшується зі зростанням температури, найбільш послідовним методом виділення необхідних параметрів значень $\varepsilon$ та $\sigma$ буде використання високотемпературних даних. При розрахунку властивостей метану на лінії сублімації і плавлення $[11,12]$ були прийняті значення параметрів ефективного потенціалу взаємодії $\mathrm{CH}_{4}-\mathrm{CH}_{4}$, наведені в роботі [10]. При $T=500 \mathrm{~K}$ значення параметрів перестають змінюватися, досягнувши $\varepsilon / k=148 \mathrm{~K}$ i $\sigma=$ $3,77 \AA$. Близькі значення $\varepsilon / k=154$ К і $\sigma=3,76 \AA$ були використані в розрахунку властивостей рідкого метану [9].

У даній роботі для розрахунків обрано наступні параметри потенціалу Леннард-Джонса $\varepsilon / k=145 \mathrm{~K}$ та $\sigma=3,725 \AA$. Значення октупольного моменту для молекули метану $-\Omega=4,5 \cdot 10^{-34}$ од. заряду/см ${ }^{3}$ було прийнято за даними роботи [12], таке ж значення октупольного моменту молекули метану було використано і в роботі [13].

Термодинамічні властивості рідкого метану були розраховані за рівняннями (1) - (3) в рамках теорії збурення в широкій області параметрів стану (інтервал температур $100-300$ К, інтервал тисків 1 -1000 МПа).

\section{4 Результати та обговорення}

У таблиці 1 наведено результати порівняння густини рідкого метану на лінії затвердіння з даними в інтервалі температур 90-105 К [1].

Порівняння розрахункових значень густини з дани ми роботи [2] наведено в таблиці 2. Автори [2] оцінюють невизначеність густини $\pm 0,03 \%$ при тисках нижче 12 МПа і температурах нижче $350 \mathrm{~K} \mathrm{i} \pm 0,03 \%$ до $\pm 0,15 \%$ для більш високих тисків і температур. Теоретичне рівняння стану, яке не привертає експериментальних даних, демонструє гарну згоду з даними роботи [2] в області високих тисків. Результати, наведені в таблиці 2, узгоджуються за густиною рідини на лінії затвердіння в межах $0,25 \%$ в інтервалі наведених даних авторами роботи [2].

Можливості теоретичного рівняння стану, що не залучає експериментальних даних, а також оцінки точності наших даних дозволяють значно розширити область дослідження рідкого метану до високих тисків понад 1000 МПа.

Рівняння стану метану внесено в автоматизовану систему розрахунку теплофізичних властивостей речовин «ThermoPro-5» [14], в рамках цієї системи розраховані термодинамічні властивості рідкого метану.

Результати розрахунку густини, ентальпії, ентропії, коефіцієнти теплового розширення, стисливості і теплоємності представлені в таблиці 3.

Таблиця 1 - Зіставлення розрахункових значень густини $\rho$ даними [1]

\begin{tabular}{|c|c|c|c|c|}
\hline \multirow{2}{*}{$T, \mathrm{~K}$} & \multirow{2}{*}{$p$, МПа } & \multicolumn{2}{|c|}{$\rho, \mathrm{\kappa г} / \mathrm{M}^{3}}$, & \multirow{2}{*}{$\delta \rho, \%$} \\
\cline { 3 - 4 } & & $\begin{array}{c}\text { дані } \\
\text { роботи [1] }\end{array}$ & $\begin{array}{c}\text { отримані } \\
\text { дані }\end{array}$ & \\
\hline 91 & 1,3 & 451,9 & 451,7 & $-0,04$ \\
\hline 92 & 5,2 & 453,2 & 453,1 & $-0,02$ \\
\hline 93 & 9,1 & 454,4 & 454,5 & 0,03 \\
\hline 94 & 13,2 & 455,7 & 455,8 & 0,02 \\
\hline 95 & 17,0 & 457,0 & 457,1 & 0,02 \\
\hline 96 & 21,5 & 458,3 & 458,3 & 0,00 \\
\hline 97 & 25,0 & 459,5 & 459,6 & 0,02 \\
\hline 98 & 30,1 & 460,8 & 460,8 & 0,00 \\
\hline 99 & 33,0 & 462,1 & 462,0 & $-0,03$ \\
\hline 100 & 39,0 & 463,4 & 463,2 & $-0,05$ \\
\hline 105 & 62,5 & 470,0 & 468,9 & $-0,24$ \\
\hline
\end{tabular}

Таблица 2 - Зіставлення розрахункових значень густини $\rho\left(\kappa г / \mathrm{M}^{3}\right)$ с табличними даними, наведеними у роботі [2]

\begin{tabular}{|c|c|c|c|c|c|c|c|c|c|c|c|}
\hline $\begin{array}{c}p, \\
\text { МПа }\end{array}$ & $\begin{array}{c}\text { Дані } \\
\text { авторів }\end{array}$ & $\begin{array}{c}\text { Дані робо- } \\
\text { ти [2] }\end{array}$ & $\delta, \%$ & $\begin{array}{c}p, \\
\text { МПа } \\
\end{array}$ & $\begin{array}{c}\text { Дані } \\
\text { авторів }\end{array}$ & \begin{tabular}{|c} 
Дані робо- \\
ти [2]
\end{tabular} & $\delta, \%$ & $\begin{array}{c}p, \\
\text { МПа } \\
\end{array}$ & $\begin{array}{c}\text { Дані } \\
\text { авторів }\end{array}$ & $\begin{array}{c}\text { Дані робо- } \\
\text { ти [2] } \\
\end{array}$ & $\delta, \%$ \\
\hline \multicolumn{4}{|c|}{$T=100 \mathrm{~K}$} & 20 & 400,56 & 402,88 & $-0,58$ & 50 & 385,24 & 387,23 & $-0,51$ \\
\hline 1 & 438,8 & 439,62 & $-0,19$ & 50 & 427,06 & 427,81 & $-0,18$ & 100 & 423,7 & 424,04 & $-0,08$ \\
\hline 10 & 445,74 & 446,02 & $-0,06$ & 100 & 456,16 & 455,37 & 0,17 & 200 & 468,82 & 467,36 & 0,31 \\
\hline 20 & 452,62 & 452,37 & 0,06 & 200 & 494,53 & 491,58 & 0,60 & & $T=$ & $200 \mathrm{~K}$ & \\
\hline \multicolumn{4}{|c|}{$T=120 \mathrm{~K}$} & \multicolumn{4}{|c|}{$T=160 \mathrm{~K}$} & 10 & 259,61 & 266,19 & $-2,47$ \\
\hline 1 & 408,3 & 410,8 & $-0,61$ & 10 & 354,15 & 358,81 & $-1,30$ & 20 & 309,31 & 313,91 & $-1,47$ \\
\hline 10 & 418,05 & 419,79 & $-0,41$ & 20 & 372,42 & 375,79 & $-0,90$ & 50 & 364,59 & 366,92 & $-0,64$ \\
\hline 20 & 427,13 & 428,24 & $-0,26$ & 50 & 406,08 & 407,55 & $-0,36$ & 100 & 408,36 & 409,03 & $-0,16$ \\
\hline 50 & 448,24 & 448,03 & 0,05 & 100 & 439,61 & 439,48 & 0,03 & 200 & 457,06 & 456,01 & 0,23 \\
\hline 100 & 473,53 & 471,72 & 0,38 & 200 & 481,24 & 479,19 & 0,43 & 500 & 532,76 & 529,46 & 0,62 \\
\hline \multicolumn{4}{|c|}{$T=140 \mathrm{~K}$} & \multicolumn{4}{|c|}{$T=180 \mathrm{~K}$} & \multicolumn{4}{|c|}{$T=220 \mathrm{~K}$} \\
\hline 1 & 373,06 & 377,51 & $-1,18$ & 10 & 313,68 & 319,56 & $-1,84$ & 10 & 180,23 & 187,59 & $-3,92$ \\
\hline 10 & 388,01 & 391,22 & $-0,82$ & 20 & 342,16 & 346,34 & $-1,21$ & 20 & 273,81 & 278,37 & $-1,64$ \\
\hline
\end{tabular}


Кінеиьь таблииі 2

\begin{tabular}{|c|c|c|c|c|c|c|c|c|c|c|c|}
\hline $\begin{array}{c}p, \\
\mathrm{MПа} \\
\end{array}$ & $\begin{array}{c}\text { Дані } \\
\text { авторів }\end{array}$ & $\begin{array}{c}\text { Дані робо- } \\
\text { ти [2] } \\
\end{array}$ & $\delta, \%$ & $\begin{array}{c}p, \\
\text { МПа }\end{array}$ & $\begin{array}{c}\text { Дані } \\
\text { авторів }\end{array}$ & $\begin{array}{l}\text { Дані ро- } \\
\text { боти [2] }\end{array}$ & $\delta, \%$ & $\begin{array}{c}p, \\
\text { МПа }\end{array}$ & $\begin{array}{c}\text { Дані } \\
\text { авторів }\end{array}$ & $\begin{array}{c}\text { Дані роботи } \\
{[2]}\end{array}$ & $\delta, \%$ \\
\hline 50 & 344,24 & 364,74 & $-5,62$ & \multicolumn{4}{|c|}{$T=260 \mathrm{~K}$} & 100 & 352,54 & 353.7 & -0.33 \\
\hline 100 & 393,58 & 394,47 & $-0,23$ & 10 & 98,27 & 101,01 & $-2,71$ & 200 & 415,07 & 414.85 & 0.05 \\
\hline 200 & 445,86 & 445,11 & 0,17 & 20 & 203,11 & 206,41 & $-1,60$ & 500 & 502,21 & 500.47 & 0.35 \\
\hline 500 & 524,5 & 521,75 & 0,53 & 50 & 305,13 & 307,59 & $-0,80$ & 1000 & 575,11 & 574.07 & 0.18 \\
\hline \multicolumn{4}{|c|}{$T=240 \mathrm{~K}$} & 100 & 365,66 & 366,78 & $-0,31$ & \multicolumn{4}{|c|}{$T=300 \mathrm{~K}$} \\
\hline 10 & 123,38 & 128,4 & $-3,91$ & 200 & 424,91 & 424,55 & 0,08 & 10 & 74,02 & 75.175 & -1.54 \\
\hline 20 & 237,2 & 241,22 & $-1,67$ & 500 & 509,3 & 507,29 & 0,40 & 20 & 153,25 & 155.28 & -1.31 \\
\hline 50 & 324,36 & 326,88 & $-0,77$ & 1000 & 580,68 & 579,45 & 0,21 & 50 & 269,55 & 271.69 & -0.79 \\
\hline 100 & 379,35 & 380,37 & $-0,27$ & \multicolumn{4}{|c|}{$T=280 \mathrm{~K}$} & 100 & 339,98 & 341.16 & -0.35 \\
\hline 200 & 435,16 & 434,63 & 0,12 & 10 & 83,82 & 85,507 & $-1,97$ & 200 & 405,63 & 405.52 & 0.03 \\
\hline \multirow[t]{2}{*}{500} & 516,71 & 514,37 & 0,45 & 20 & 174,93 & 177,57 & $-1,49$ & 500 & 495,4 & 493.9 & 0.30 \\
\hline & & & & 50 & 286,79 & 289,11 & $-0,80$ & 1000 & 569,75 & 568,89 & 0,15 \\
\hline
\end{tabular}

Таблиця 3 - Термодинамічні властивості рідкого метану

\begin{tabular}{|c|c|c|c|c|c|c|c|}
\hline $\begin{array}{c}p, \\
\text { МПа }\end{array}$ & $\begin{array}{c}\rho, \\
\kappa \Gamma / \mathrm{M}^{3}\end{array}$ & $\begin{array}{c}h, \\
\text { кДж/моль }\end{array}$ & $\begin{array}{c}s, \\
\text { Дж/мольК }\end{array}$ & $\begin{array}{c}\alpha_{P} \\
1 / \mathrm{KK}\end{array}$ & $\begin{array}{c}\beta_{T}, \\
1 / \Gamma \Pi а \\
\end{array}$ & $\begin{array}{c}C_{V}, \\
\text { Дж/(моль·К) } \\
\end{array}$ & $\begin{array}{c}C_{P}, \\
\text { Дж/(моль } \cdot \text { К) }\end{array}$ \\
\hline \multicolumn{8}{|c|}{$T=100 \mathrm{~K}$} \\
\hline 1 & 438,80 & 3,30 & 26,211 & 3,298 & 1,8668 & 43,979 & 45,306 \\
\hline 10 & 445,74 & 3,52 & 25,183 & 3,014 & 1,6304 & 44,242 & 45,491 \\
\hline 20 & 452,62 & 3,77 & 24,150 & 2,779 & 1,4395 & 44,516 & 45,702 \\
\hline 30 & 458,83 & 4,03 & 23,205 & 2,601 & 1,2956 & 44,776 & 45,913 \\
\hline \multicolumn{8}{|c|}{$T=200 \mathrm{~K}$} \\
\hline 1 & 10,26 & 15,45 & 111,118 & 5,970 & 1063,27 & 33,698 & 34,351 \\
\hline 10 & 259,61 & 10,58 & 73,263 & 12,606 & 34,9834 & 37,157 & 40,656 \\
\hline 100 & 408,36 & 11,73 & 58,873 & 1,844 & 1,6194 & 39,841 & 40,869 \\
\hline 200 & 457,06 & 14,32 & 53,346 & 1,254 & 0,8196 & 41,883 & 42,723 \\
\hline 500 & 532,76 & 22,09 & 43,927 & 0,801 & 0,3412 & 45,811 & 46,517 \\
\hline \multicolumn{8}{|c|}{$T=300 \mathrm{~K}$} \\
\hline 1 & 6,46 & 19,76 & 128,691 & 3,523 & 1025,494 & 33,368 & 33,931 \\
\hline 10 & 74,02 & 18,43 & 106,108 & 5,591 & 111,1844 & 34,429 & 35,568 \\
\hline 100 & 339,98 & 17,22 & 81,15 & 1,804 & 2,8301 & 37,241 & 38,256 \\
\hline 500 & 495,40 & 27,54 & 66,10 & 0,674 & 0,4148 & 42,083 & 42,745 \\
\hline 1000 & 569,75 & 40,03 & 57,826 & 0,461 & 0,1954 & 45,402 & 45,974 \\
\hline
\end{tabular}

\section{Література}

1. Термодинамические свойства метана: ГСССД. Серия монографии / В. В. Сычев, А. А. Вассерман, В. Л. Загорученко, Л. Д. Козлов, Г. А. Спиридонов, В. А. Цымарный - М.: Издательство стандартов, 1979. - 348 с.

2. Setzmann, U., Wagner, W. (1991). A New Equation of State and Tables of Thermodynamic Properties for Methane Covering the Range From the Melting Line to $625 \mathrm{~K}$ at Pressures up to $1000 \mathrm{MPa}$. Journal of Physical and Chemical Reference Data, 20(6), 1061-1155. DOI: https://doi.org/10.1063/1.555898

3. Benedict, M., Webb, G.; Rubin, L. (1940), An Empirical Equation for Thermodynamic Properties of Light Hydrocarbons and Their Mixtures: I. Methane, Ethane, Propane, and n-Butane, Journal of Chemical Physics, 8 (4): 334-345, doi: 10.1063/1.1750658

4. Barker J.A., Henderson D. // J. Chem. Phys. - 1967. 47, N 8. - P. 2856 - 2861

5. Weeks J.D., Chandler D., Andersen H.C. // J. Chem. Phys. -1971 - 30, N 12. - P. 5237 - 5247

6. Gubbins K. E., Grey C.G. Perturbation theory for the angular correlation function of molecular fluid. Moler. Phys., 23, №1, 187 - 192, 1972. DOI: http://dx.doi.org/ 10.1080/00268977200100171

7. J. Kolafa, I. Nezbeda, Fluid Phase Equilib. 100, 1 (1994). doi:10.1016/0378-3812(94)80001-4

8. Yakub L. N., Bodiul O. S. Melting Line Parameters and Thermodynamic Properties of Methane at High Pressures., Journal of Low Temperature Physics. - 2017. - Vol.187, 
№1. - P.33-42,

9. Cheng V.M. Daniels W, B. Crawford R.K, Melting parameters of methane and nitrogen from 0 to $10 \mathrm{kbar}$. Phys. Rev. B11, №10, 3972 - 3975, 1975

10. Yakub L. N., Bodiul O. S. Low-temperature equation of state of solid methane // Холодильна техніка та технологія. - 2016. - Т. 52.- № 1.- С. 80-85. DOI: 10.21691/ret.v52i1.46

11. Якуб Л.Н., Бодюл Е.С. Термодинамические свойства метана при высоких давлениях, Технические газы, T. 16, № 2, 2016.
12. D. E. Stogryn, A. P. Stogryn. Molecular Multipole Moments. Mol. Phys. 11, 371 (1966). doi:10.1080/00268976600101201

13. Прохватилов А. И., Гальцов Н. Н., Клименко Н. А., Стржемечный М. А.. Структура твердых фаз $\mathrm{SiH}_{4}$ // Физика низких температур. - 2008, Т. 34, № 2, С. $185-$ 196.

14. Бодюл Е. С. Автоматизированная система для определения теплофизических свойств технических веществ. Холодильная техника и технология. - 2017. - Т. 53.№ 4.- C. 72-77. DOI https://doi.org/10.15673/ret.v53i5.857

\title{
Equation of state of condensed methane at high pressures
}

\author{
L. N. Yakub, O. S. Bodiul
}

Odessa National Academy of Food Technologies, 112 Kanatnaya str., Odessa, 65039, Ukraine

\begin{abstract}
The theoretical equation of state of liquid methane constructed within the framework of perturbation theory, where the Lennard-Jones fluid acts as a zero approximation, and the octupole-octupole interaction of methane molecules as a potential of perturbation is proposed. The equation of state of liquid methane allows us to describe its thermodynamic properties on the melting line and to predict them with sufficient accuracy in the region of high pressure, where practically there are no experimental data. The thermodynamic properties of liquid methane are calculated over a wide range of temperatures $(100-300 \mathrm{~K})$ and pressures $(1-1000 \mathrm{MPa})$. only three parameters were given for calculation: two parameters of the Lennard-Johns potential and an octopal momentum of the methane molecule. The equations of state of methane are introduced into the automated system for calculating the thermophysical properties of substances "ThermoPro-5". The results of calculation of density, enthalpy, entropy, coefficient of thermal expansion, compressibility and heat capacity are presented. The possibilities of the proposed theoretical state equation, which does not attract experimental data, as well as the accuracy of the data obtained, allow us to significantly expand the field of study of liquid methane to high pressures above $1000 \mathrm{MPa}$.
\end{abstract}

Keywords: methane, equation of state, high pressures, melting line, density.

\section{References}

1. Termodynamycheskye svoistva metana: HSSSD. Seryia monohrafyy / V. V. Sychev, A. A. Vasserman, V. L. Zahoruchenko, L. D. Kozlov, H. A. Spyrydonov, V. A. Tsymarnyi - M.: Yzdatelstvo standartov, 1979. - $348 \mathrm{~s}$.

2. Setzmann, U., Wagner, W. (1991). A New Equation of State and Tables of Thermodynamic Properties for Methane Covering the Range From the Melting Line to $625 \mathrm{~K}$ at Pressures up to $1000 \mathrm{MPa}$. Journal of Physical and Chemical Reference Data, 20(6), 1061-1155. DOI: https://doi.org/10.1063/1.555898

3. Benedict, M., Webb, G.; Rubin, L. (1940), An Empirical Equation for Thermodynamic Properties of Light Hydrocarbons and Their Mixtures: I. Methane, Ethane, Propane, and n-Butane, Journal of Chemical Physics, 8 (4): 334-345, doi: 10.1063/1.1750658

4. Barker J.A., Henderson D. (1967) J. Chem. Phys., 47(8), 2856-2861

5. Weeks J.D., Chandler D., Andersen H.C. (1971) J. Chem. Phys., 30(12), 5237 - 5247

6. Gubbins K. E., Grey C.G. (1972) Perturbation theory for the angular correlation function of molecular fluid. Moler. Phys., 23(1), 187-192. DOI: http://dx.doi.org/ $10.1080 / 00268977200100171$

7. Kolafa J., Nezbeda I. (1994) Fluid Phase Equilib., 100(1) doi: 10.1016/0378-3812(94)80001-4
8. Yakub L. N., Bodiul O. S. (2017). Melting Line Parameters and Thermodynamic Properties of Methane at High Pressures., Journal of Low Temperature Physics, 187(1), 33-42. Doi: https://doi.org/10.1007/s10909-016-1721-7

9. Cheng V.M. Daniels W.B., Crawford R.K. (1975) Melting parameters of methane and nitrogen from 0 to $10 \mathrm{kbar}$. Phys. Rev. B11, no. 10, 3972-3975.

10. Yakub L. N., Bodiul O. S. (2016). Low-temperature equation of state of solid methane. Refrigeration Engineering and Technology, 52(1), 80-85. DOI: 10.21691/ ret.v52i1.46

11. Yakub L. N., Bodiul O. S. (2016). Thermodynamic properties of methane at high pressures. Tekhnicheskie gazy, 16(2), 2016. DOI: https://doi.org/10.18198/j.ind.gases. 2016.0818

12. Stogryn D. E., Stogryn A. P. (1966) Molecular Multipole Moments. Mol. Phys. 11, 371. doi: 10.1080/ 00268976600101201

13. Прохватилов А. И., Гальцов Н. Н., Клименко Н. А., Стржемечный М. А. Структура твердых фаз $\mathrm{SiH}_{4} / /$ Физика низких температур. - 2008, Т. 34, № 2, С. 185-196.

14. Bodiul E. S. (2017). Automated System for Determination of Thermophysical Properties of Technical Substances. Refrigeration Engineering and Technology, 53(4), 72-77. DOI https://doi.org/10.15673/ret.v53i5.857

Received 12 May 2018 Approved 03 July 2018 Available in Internet 30 August 2018 